\title{
EL ESCULTOR ANTONIO SUSILLO Y EL RETRATO DEL PRIMER CONDE DE YBARRA
}

\author{
THE SCULPTOR ANTONIO SUSILLO AND THE \\ PORTRAIT OF THE FIRST EARL OF YBARRA
}

\author{
JosÉ Luis RoMero TORRES \\ Consejería de Cultura, Junta de Andalucía. España \\ joseluisromerotorres@gmail.com
}

\begin{abstract}
Antonio Susillo fue uno de los escultores españoles más destacados de finales del siglo XIX por su habilidad en el modelado del barro. En su producción artística, los temas del retrato y de los monumentos públicos de exaltación histórica o social fueron fundamentales. En este estudio hemos seleccionado algunas valoraciones favorables que recibió en vida por los retratos que hizo y analizamos el retrato del primer conde de Ybarra que modeló, cuya composición nos sugiere que fue concebido como proyecto de monumento público que no se realizó.

Palabras claves: escultura; retrato; monumento público; Antonio Susillo; conde de Ybarra.
\end{abstract}

Antonio Susillo was one of the most outstanding Spanish sculptors of the late $19^{\text {th }}$ century for his skill in clay modeling. Subjects of portraiture and public monuments of historical or social exaltation were fundamental in his artistic production. We have selected in this paper some favorable appreciations that he received in life for the portraits that he made and we also analyze the portrait of the first Earl of Ybarra that he modeled, whose composition suggests that it was conceived as a public monument project that was not realized.

Keywords: sculpture; portrait; public monument; Antonio Susillo; Earl of Ybarra.

\section{LA FORTUNA CRÍTICA DE UNA CARRERA ARTÍSTICA FRUSTRADA}

El escultor sevillano Antonio Susillo fue un destacado artista de finales del siglo XIX con gran habilidad en la técnica del modelado y uno de los principales representantes de la escultura de su época que decidió truncar su vida

* A la memoria de mi hermano Francisco José (†2013). 
inesperadamente. Además de los temas costumbristas, las escenas históricas y el retrato, su nombre ha quedado vinculado al fenómeno urbano del monumento público, cuyo objeto fundamental es la exaltación social de un personaje de la sociedad contemporánea o de la historia pasada. Antonio Susillo nació el 16 de abril de 1855 y murió el 22 de diciembre de $1896^{1}$.

En los días previos a la Navidad de 1896 nadie pudo imaginar la trágica muerte de este artista. A pesar de su corta y frustrada vida, pues se suicidó a la edad de 41 años, fue el escultor oficial de la burguesía sevillana durante casi veinte años. En vida fue muy elogiado por la crítica, como reflejan cuatro publicaciones locales dadas a la luz en la corta vida del artista y una cuarta referencia en una edición nacional. Antonio Susillo vivió pocos años, pero fueron suficientes para alcanzar el reconocimiento nacional. Él y el artista barroco Juan de Mesa fueron dos escultores que, a pesar de sus cortas trayectorias profesionales, lograron crear una suficiente producción de gran calidad artística, lograda en pocos años, como si hubieran intuido que la vida no les iba a ofrecer los años necesarios para un desarrollo vital más prolongado.

El primer historiador y crítico de arte que incluyó una valoración suya favorable fue Manuel Ossorio y Bernard en la segunda edición ampliada de la Galería de artistas españoles del siglo XIX, publicada en 1884, cuando el artista tenía tan solo 29 años de edad. Algunos de esos datos han seguido repitiéndose en los resúmenes biográficos: sus inicios junto a su padre, almacenista de aceitunas, su descubrimiento por el pintor José de la Vega, sus primeros trabajos-Bajo la Esfinge, Últimos momentos de una cortesana y Una hebrea huyendo de la persecución-, la medalla de bronce en 1879 en una exposición de Cádiz, la Alegoría modelada en barro que envió en 1882 a la exposición organizada en Madrid por el señor Hernández, la protección del príncipe ruso Giedroic para su viaje a París en 1883 y la relación de obras de aquellos años con indicación de su propietario. Ossorio termina valorando la calidad artística de sus obras que "permiten augurar a este joven artista excelente porvenir"2.

En 1885 Luis Montoto y Pereyra publicó el primer libro sobre Susillo, cuando el artista contaba solo 30 años. Era el reflejo del impacto social y cultural de esta promesa artística ${ }^{3}$, quien tres años antes aparecía en la prensa local. Los medios impresos informaban de dos noticias: la primera, la visita que la reina Isabel había hecho al estudio del artista; y, la segunda, la invitación que el príncipe ruso Giedroik, gran aficionado a las artes plásticas, había hecho a Susillo para que

\footnotetext{
1 ÁLVAREZ CRUZ, Joaquín: "Notas biográficas sobre el escultor Antonio Susillo", Laboratorio de Arte, 10, 1997, p. 523.

2 OSSORIO Y BERNARD, Manuel: Galería biográfica de artistas españoles del siglo XIX. Madrid, 1883-1884 (reed. facsímil, 1975), p. 654.

${ }^{3}$ MONTOTO Y PEREYRA, Luis: Antonio Susillo. Obras de este notable escultor. Sevilla, 1885 .
} 
visitara su palacio de París. En la monografía escrita por Montoto se narra el origen del proyecto de monumento conmemorativo de los acontecimientos del Dos de Mayo. El Ayuntamiento le había encargado el monumento de Daoiz, en cuya obra trabajaba el artista como anuncia el historiador, quien además describe los dos grandes relieves que llevaría ${ }^{4}$. Montoto valoró los retratos calificándolos de "innumerables", y mencionó el del capitán general Polavieja, los de la familia del marqués de Pickman, el de la duquesa de Alba y el del "difunto José María Ibarra". Esta última obra es la que estudiamos en este artículo.

Entre la publicación de Luis Montoto y la de José Cascales, diez años después, se forjó toda la trayectoria artística de Antonio Susillo que transcurrió con numerosos encargos de particulares, de instituciones públicas y de colectivos sociales. Por el desafortunado desenlace de su vida, estos reconocimientos no fueron suficientes para satisfacer los sueños triunfadores del escultor.

En 1895, un año antes del suicidio, José Cascales Muñoz escribió la segunda biografía de Susillo incluida en el libro titulado Sevilla Intelectual (1895-1896) ${ }^{5}$. En el apéndice realizó un breve comentario de los jóvenes escultores, dedicando especial atención a los discípulos de Susillo: Fernando de la Cuadra, Miguel Sánchez Dalp, Lorenzo Coullat Valera y Viriato Rull ${ }^{6}$. Años después, este mismo historiador amplió los datos biográficos en una historia de las Bellas Artes de Sevilla, incluyendo el suceso trágico de su muerte ${ }^{7}$.

En el mismo año de su muerte, antes de que el artista decidiera suicidarse, se publicó otro libro sobre pintores y escultores sevillanos, escrito por Eugenio Sedano, en el que se le incluía como era lógico ${ }^{8}$. Este texto no aporta nuevos datos sobre Susillo, pues solo es un texto literario que ensalza la figura del artista, su habilidad y las sensaciones que el escritor quiso transmitir con motivo de su visita al taller del escultor. Sedano acaba dejándonos un retrato sicológico de Susillo: "Desde hace poco, el genio comparte sus triunfos con una esposa amante, a la que ha entregado su corazón. Seguramente aquella tristeza de su dulce mirar habrá desaparecido, y el artista, halagado por las afecciones, tendrá desde hoy mayor amplitud para mostrarse tal como le permiten sus energías de potente imaginación". Ni Cascales ni Sedano pudieron imaginar el trágico final, aunque

${ }^{4}$ Ibidem, pp. 29-30.

5 CASCALES MUÑOZ, José: Sevilla Intelectual. Sus escritores y artistas contemporáneos. Madrid, 1896, pp. 471-479.

${ }^{6}$ Ibidem, pp. 557-558.

${ }^{7}$ CASCALES MUÑOZ, José: Las Bellas Artes Plásticas en Sevilla. La pintura, la escultura y la cerámica artística desde el siglo XIII hasta nuestros días. Apuntes históricos y biográficos. T. II. Toledo, 1929, pp. 44-50.

8 SEDANO, Eugenio: Estudio de estudios. Artículos-siluetas de pintores y escultores sevillanos. Sevilla, 1896, pp. 49-52.

${ }^{9}$ Ibidem, p. 51. 
los dos destacaron su carácter depresivo. Susillo tampoco fue muy afortunado en los concursos de las Exposiciones Nacionales, siendo segundo premio en los años 1887 y 1890.

La fortuna crítica de la vida y obra de Antonio Susillo posterior ha tenido tres momentos destacados: una revalorización en la década de 1920, la publicación del volumen sobre la escultura del siglo XIX de la colección Ars Hispaniae en 1958 y principalmente los artículos de las últimas décadas del siglo XX y comienzos del XXI.

\section{RETRATO O PROYECTO FRUSTRADO DE MONUMENTO PÚBLICO DEL PRIMER CONDE DE YBARRA MODELADO POR ANTONIO SUSILLO}

Cuando falleció don José María de Ybarra, primer conde de su apellido, el escultor Antonio Susillo tenía tan solo 23 años de edad y era una joven promesa artística de Sevilla. Los herederos de este vasco "sevillanizado" conservan un retrato escultórico modelado en barro por este artista sevillano, cuya obra mencionó Luis Montoto en la primera biografía que se escribió sobre Susillo, publicada en 1885: "había hecho algunos retratos... entre ellos el del difunto José María Ibarra"10. Susillo concibió la escultura como un pequeño monumento alegórico que refleja las actividades sociales, culturales, asistenciales, etc., por las que don José María alcanzó la popularidad en Sevilla y en su tierra vasca. El grupo escultórico está modelado en barro y se compone del retrato en busto sobre un pilar cuadrado y de figuras de bulto, objetos y relieves colocados alrededor del pilar que simbolizan y exaltan los valores sociales del homenajeado (Figura 1).

\section{Semblanza de la vida y virtudes sociales de don José María de Ybarra}

El empresario y político vasco don José María de Ybarra Gutiérrez de Caviedes ${ }^{11}$ nació en Bilbao en 1816 y murió en Sevilla en 1878. Estudió Derecho en la Universidad de Madrid, doctorándose a los 25 años. Con esa edad participó, junto a su hermano Juan, en el levantamiento de O'Donnell contra los progresistas de Espartero. En 1842 se trasladó a Andalucía por asuntos de negocios familiares, terminando por instalarse en Sevilla donde permaneció el resto de su vida, treinta y cinco años, llegando a formar parte de la historia contemporánea de la

${ }^{10}$ MONTOTO Y PEREYRA, L.: Antonio Susillo..., op. cit., p. 29.

${ }^{11}$ El primer apellido se escribe con "Y" en la documentación vasca y sevillana de la época, y de esa forma se escribe y sigue apareciendo en las publicaciones recientes, pero en Sevilla se ha castellanizado en "I". Su tercer apellido aparece escrito indistintamente con "v" o "b" en la documentación de la época y en las publicaciones del siglo XX. 
ciudad de la Giralda. Falleció el 14 de mayo de 1878, un año después de que el rey Alfonso XII le concediera el título nobiliario de conde ${ }^{12}$.

Don José María vivió en una época de fuertes enfrentamientos políticos entre conservadores y liberales que estuvo marcada por la alternancia política de Espartero, O'Donnell, Bravo Murillo y, por último, Cánovas del Castillo. Él alternó los negocios particulares con su compromiso político como conservador, desempeñando importantes cargos públicos en Sevilla, como la alcaldía de la ciudad de 1875 a 1877. Además de los méritos sociales y económicos, el empresario vasco alcanzó gran popularidad por su dimensión humana y católica, pues ayudó personalmente a los niños desamparados y a las personas necesitadas con ayudas económicas, contribuyendo a la mejora de asilos y hospitales ${ }^{13}$. Entre otros acontecimientos de la ciudad fue el impulsor de la Feria de Abril y de otras fundaciones que desarrollamos en el análisis del grupo escultórico de Antonio Susillo.

\section{La muerte del primer conde de Ybarra}

Don José María de Ybarra, primer conde de Ybarra, murió el 14 de mayo de 1878. El diario El Porvenir publicó la noticia al día siguiente en la sección "Gacetillas": "A la una de la madrugada de ayer ha dejado de existir el Sr. D. José María Ibarra y Gutiérrez de Caviedes. Sevilla ha perdido a uno de sus hijos adoptivos más ilustres y más benéficos, cuyo corazón estaba siempre abierto a los sentimientos más nobles y generosos y cuya mano era, puede decirse, la providencia de nuestros hospitales. En el día de ayer la ciudad entera, sin distinción de clases, seguía con dolorosa inquietud los progresos del terrible padecimiento..." ${ }^{14}$. El funeral se celebró en la parroquia de San Nicolás y fue enterrado en la iglesia del Hospital Central de Sevilla, antiguo Hospital de las Cinco Llagas, con autorización del gobierno central. La información de la prensa termina comentando: "premio debido a sus actos benéficos a favor de dicho establecimiento y de todos los demás de su misma índole". Este diario dedicó una amplia descripción del funeral en el segundo día ${ }^{15}$ que fue modesta, como había pedido el conde en su testamento, aunque tuvo una numerosa concurrencia.

El duelo fue presidido por sus familiares, el hermano mayor de la Hermandad de la Santa Caridad y primeras autoridades, como el gobernador civil. El

${ }^{12}$ Concesión fechada el 6 de junio de 1877. GONZÁLEZ-DORIA, Fernando: Diccionario heráldico y nobiliario de los reinos de España. Madrid, 1987, p. 154.

13 YBARRA YBARRA, Eduardo e YBARRA HIDALGO, Eduardo: Notas sobre José María Ybarra, I Conde de Ybarra. Sevilla, 1984; DÍAZ MORLÁN, José María: Los Ybarra: una dinastía de empresarios, 1801-2001. Madrid, 2002, capítulo 6 dedicado a "El Conde de Ibarra y la familia de Sevilla", pp. 129-142; y DE YBARRA E YBARRA, Javier: Nosotros, los Ybarra: Vida, economía y sociedad (1744-1902). Barcelona, 2002.

14 ANÓNIMO: "Gacetillas”, El Porvenir, 15-5-1878, p. 2.

15 Ibidem, 16-5-1878, p. 2. 
cadáver fue llevado en andas por los hermanos de la Santa Caridad, cumpliendo una de las reglas caritativas de la institución, que eran seguidos por los músicos del Asilo de Mendicidad de San Fernando y unas cuatrocientas personas entre ancianos y niños de esta institución asistencial. Al pasar por la feligresía de San Roque, los niños y niñas de las escuelas públicas de la parroquia, que había sido la última fundación realizada por el difunto, manifestaron una gran prueba de gratitud. Después, en la puerta de la Macarena fue recibido por el director del Hospital Central y por las Hermanas de la Caridad, quienes acompañaron al féretro hasta el interior de la iglesia del hospital, donde fue sepultado en la capilla que se le había concedido.

La junta directiva de la Asociación Sevillana de Amigos de los Pobres, celebrada el mismo día de la defunción del conde y presidida por Agustín María de la Cuadra, acordó expresar demostraciones de pésame y gratitud, celebrando honras en sufragio por el alma de don José María de Ybarra en la iglesia parroquial de San Julián ${ }^{16}$. Además solicitaron a la familia una fotografía del benefactor para colocarla en la sala de sesiones de esta institución y autorización para que la Asociación pudiera escribir y publicar su biografía. La Sociedad Económica de Amigos del País, que hasta entonces dirigía el difunto conde, celebró también sesión, quedando la silla presidencial vacía en respeto por su muerte. El vicedirector don Francisco de Paula Collantes de Terán hizo una semblanza biográfica del fallecido ${ }^{17}$. Como había sido alcalde, el Ayuntamiento presidido por García de Leaniz acordó en su sesión de 17 de mayo transmitir el pésame de la corporación a los herederos por su muerte, nombrando una comisión para ello ${ }^{18}$.

\section{El retrato de don José María de Ybarra}

Después de la muerte de don José María de Ybarra, primer conde de su ape1lido, el escultor Antonio Susillo realizó un retrato del ilustre vasco, cuya configuración general nos sugiere que, sin duda, fue realizado como boceto o proyecto para un monumento público dedicado al alcalde, benefactor e ilustre personaje de la historia de Sevilla. El retrato es un busto del homenajeado colocado sobre un pilar cuadrado. La obra, modelada en barro sin policromar, representa al conde con aspecto noble y mirada serena en edad aproximada de sesenta años, pues murió cuando tenía sesenta y dos. La cabeza presenta un potente volumen de forma redondeada con una amplia calva, cejas ligeramente arqueadas y rostro de marcados rasgos fisonómicos. El conde viste chaqueta adornada con varias medallas que reflejan los méritos profesionales, sociales y políticos obtenidos: lleva dos de

16 ANÓNIMO: "Asociación Sevilla de Amigos de los Pobres", El Porvenir, 18, 22 y 23-5-1878, p. 3.

17 ANÓNIMO: "Sociedad de Amigos del País", El Porvenir, 19-5-1878, p. 2.

${ }_{18}$ Archivo Municipal de Sevilla (A.M.S.), Actas Capitulares, 17-5-1878, f. 129v. 
tamaño grande y forma circular en su costado izquierdo, más una de menor tamaño en la solapa y otras dos medallas alargadas que lleva colgadas sobre el pecho bajo la pajarita que cierra el cuello de la camisa (Figura 2).

Don José María de Ybarra recibió condecoraciones y nombramientos, entre ellos la Cruz de los Defensores de Bilbao en 1836 por haber participado en la Milicia Nacional durante el sitio que se realizó en la ciudad vasca; varios títulos de académico - Real y Eclesiástica de San Pedro en 1841, Real de Bellas Artes de Sevilla desde 1855 y Real de Jurisprudencia y Legislación- y fue nombrado caballero de la Orden de Beneficencia. Desempeñó importantes cargos públicos. Fue presidente de la Diputación, de la Junta Provincial de Beneficencia y de la Real Sociedad Económica de Amigos del País, director del Banco de Sevilla, cónsul de México y del Tribunal de Comercio y, por último, alcalde de Sevilla al final de su vida, aunque en el año 1846 ocupó interinamente la presidencia de la alcaldía. La presencia del escudo heráldico del homenajeado, rematado por la corona de conde y colocado debajo del busto en el lado principal del pilar, reafirma los honores recibidos.

\section{Los referentes sevillanos}

El nombre de don José María de Ybarra está vinculado a la fundación de la Feria de Abril de Sevilla, del Asilo de San Fernando, así como a la gestión del Hospital Central y a la ayuda de enfermos y a niños pobres.

La exaltación de su virtud caritativa y un nuevo concepto de alegoría de la Caridad. En el lado principal o frente del monumento, Susillo ha situado una mujer sentada y vestida con traje de la época que lleva un gran escote recto de tirantas, decorado con lazos y un medallón ovalado en el centro del pecho con la palabra "Charitas". El escultor ha representado una alegoría de la Caridad con una composición distinta a la realizada en la Edad Moderna, en la que una mujer se encuentra rodeada de niños. Con ella el artista exalta y recuerda la acción caritativa del homenajeado. Esta figura femenina de gran belleza y sensualidad, que lleva la cabeza alta mirando al cielo, muestra un peinado con raya en medio con unos cabellos ondulados en la frente y otros recogidos en cola, que caen por la espalda. La mujer sujeta un libro abierto de grandes dimensiones con sus manos apoyándolo en posición horizontal sobre las piernas con un texto alusivo al Asilo de San Fernando, del que fue fundador (Figura 2).

Susillo exaltó la caridad cristiana de don José María de Ybarra y su preocupación por ayudar a los niños pobres modelando un bajorrelieve con forma de tondo situado al lado derecho de la anterior figura. La escena representa la fachada de una escuela con un grupo de niños. Recordemos que los escolares de la parroquia de San Roque mostraron su agradecimiento y respeto durante el paso de la carroza fúnebre de su fundador por delante de aquella institución. El escultor vuelve a demostrar su habilidad con los palillos de modelar dejándonos una 
representación de escaso volumen muy aplanado en el que conjuga las pequeñas formas de los cuerpos de los niños con los planos y las incisiones con las que representa los elementos arquitectónicos y su perspectiva. Susillo dejó constancia de su dominio de la técnica del stiacciato, como Donatello puso de moda en el Renacimiento, realizando el bajorrelieve con un sutil modelado de grosor milimétrico para crear texturas y formas.

La Feria de Abril. Otro referente sevillano presente en esta escultura tenía que ser, sin duda, la referencia a la Feria de Abril en la que participó como uno de los importantes impulsores y por la que don José María de Ybarra ha pasado a la historia local de Sevilla, cuya fiesta se ha convertido en un evento de alcance internacional ${ }^{19}$. Este vasco y un catalán, dos políticos con formación empresarial, fueron los creadores de este acontecimiento social y económico. El conde de Montelirios desempeñaba el cargo de alcalde en 1846 cuando el Ayuntamiento, en su sesión 25 de agosto, acordó solicitar a la reina Isabel II la autorización para celebrar una feria agrícola en primavera, concretamente en abril, a propuesta de los regidores don José María de Ybarra y don Narciso Bonaplata para favorecer la economía y el sector agrícola y ganadero ${ }^{20}$. La reina concedió el permiso y en 1847 se celebró la primera Feria de Abril en el prado de San Sebastián ${ }^{21}$. Aunque se menciona en la propuesta como feria agrícola, los premios que se otorgaban eran tanto para los que presentaban las mejores lanas, como para los que mostraran mejores bueyes y carneros jóvenes y caballos más rápidos. Esta feria tuvo una segunda etapa de carácter refundacional en 1874.

Para incluir su referencia en este monumento, Susillo colocó sobre el pilar, a modo de cartela realizada con superficie de modelado blando y suaves ondulaciones, la representación de una vista de la Feria en el prado de San Sebastián con las casetas en primer término y la Giralda al fondo, como elemento identificador de la ciudad a la que corresponde (Figura 3). En este asunto, Susillo sigue la tradición de algunos pintores como Andrés Cortés Aguilar ${ }^{22}$ y Manuel Rodríguez de

${ }^{19}$ SALAS, Nicolás: Las Ferias de Sevilla. Sevilla, 1974 (2ª edición, 1992).

20 A.M.S., Actas Capitulares, 25-8-1846, ff. 222v-226v. SALAS, N.: Las Ferias de Sevilla, op. cit., pp. 26-29.

${ }^{21}$ CHAVES REY, Manuel: El primer año de Feria en Sevilla (1847), apuntes históricos. Sevilla, 1914.

${ }^{22}$ QUESADA, Luis: Los Cortés. Una dinastía de pintores en Sevilla y Francia entre los siglos XVIII y XX. Sevilla, 2001, pp. 46-48, láms. 40-41 y 45. Entre las versiones conocidas destacamos las tres vistas de La Feria de Sevilla pintadas por Andrés Cortés Aguilar, dos de ellas fechadas en 1852 y 1856 (Herederos de Ybarra, Ayuntamiento de Sevilla y Museo de Bellas Artes de Sevilla). Este pintor también retrató a don José María de Ybarra en los primeros años de su estancia en Sevilla, lám. 16. CARRETE PARRONDO, Juan: "Estampas de Sevilla. Recorrido a través de las técnicas del arte gráfico", en Iconografía de Sevilla, 1790-1868. Madrid, 1991, pp. 298 y 334, cat. 241 y 293. 
Guzmán ${ }^{23}$, o de los litógrafos de la época, como el álbum de Antonio Chaman y Carlos Santigosa, las estampaciones de Vicente Urrabieta ${ }^{24}$ y la litografía firmada por J.E.G. ${ }^{25}$ La técnica que el escultor empleó es una combinación de huecograbado en el caso de la Giralda y de las casetas del fondo con relieves de escaso volumen los elementos situados en el primer plano.

\section{El referente vasco}

A la izquierda de la alegoría y colocado sobre el suelo hay un gran jarrón cuyo aspecto y texturas sugieren que reproduce uno de bronce. Este objeto simboliza el reconocimiento social y político por otro hecho caritativo que tuvo don José María de Ybarra en 1860 con los soldados de su país de origen (Figura 4).

En 1859 el general Leopoldo O’Donnell, como presidente del Gobierno de la Unión Liberal, firmó un acuerdo diplomático con el sultán de Marruecos sobre la soberanía española de Melilla, Alhucemas y Vélez de la Gomera. En aquel acuerdo no se incluyó Ceuta, por lo que España decidió reforzar la fortificación de esa ciudad. Este gesto provocó el descontento de la población marroquí y el inicio de un enfrentamiento bélico que ha sido enjuiciado, por unos historiadores, como una acción de defensa de la soberanía española y, por otros, como una acción del gobierno para terminar con las intrigas políticas y los intentos de pronunciamiento militar, desviando la ambición de los altos cargos del ejército hacia las condecoraciones y ascensos concedidos por el gobierno. Esta primera guerra de Marruecos o guerra de África generó un movimiento patriótico con la organización de grupos de reclutamiento de voluntarios en el País Vasco y en Cataluña para participar en el frente. Asimismo, esta guerra sirvió al gobierno para mejorar su política exterior.

El conflicto surgió en agosto de 1859, en el mismo mes que murió el sultán Muley Abderramán, aunque la declaración de guerra fue aprobada por las Cortes en octubre. Durante los siguientes meses los tres cuerpos del ejército español desembarcaron en sucesivas fase en el norte de África, produciéndose distintas batallas importantes como la de Castillejos. En febrero de 1860, a la vez que las tropas españoles toman Tetuán y la flota bombardea los puertos de Larache, Rabat y Arcila, en Sevilla don José María de Ybarra costeó de su hacienda particular la instalación de un hospital para atender a los heridos de los Tercios Vascongados.

En marzo fue decisiva la victoria en la batalla de Wad-Ras, que se produjo el día 23. Dos días después se firmó un armisticio entre los dos países y un mes

${ }^{23}$ Ibidem, p. 299, cat. 242. MÉNDEZ RODRÍGUEZ, Luis: Manuel Rodríguez de Guzmán. Sevilla, 2000, pp. 116-117, lám. 3.

${ }^{24}$ CARRETE PARRONDO, J.: “Estampas de Sevilla...”, op. cit., p. 296, cat. 238.

${ }_{25}$ Ibidem, p. 71, fig. 53, litografía fechada hacia 1852, Biblioteca Nacional de Madrid. 
después el tratado de Wad-Ras, por el que España fue reconocida como vencedora y beneficiaria de compensaciones económicas y territoriales.

El gesto altruista y caritativo de don José María hacia sus paisanos fue el motivo de su nombramiento de "Padre de Provincia" por la Junta General de las provincias vascas en su sesión de 22 de julio celebrada en Guernica. Este reconocimiento fue ampliado por la Diputación de Guipúzcoa, cuyo organismo comunicó este gesto a todos los alcaldes y párrocos para que lo divulgaran en sus tablones informativos. Estos honores fueron acompañados del regalo de un jarrón de bronce con escenas bélicas referentes a la guerra de África, que Susillo reprodujo en este conjunto escultórico entre la alegoría de la Caridad y la figura que auxilia a un soldado herido. Este objeto está compuesto de tres niveles, en el inferior o base del jarrón, hay dos figuras pequeñas que representa a un soldado herido acompañado de otro sentado a su lado; en el siguiente nivel, que es la panza de la copa, se representa un escudo con un resplandor solar alusivo al patriotismo; y en el superior o cuello de la copa se representa la escena de una batalla entre un grupo de soldados a pie que se defienden disparando con escopeta y otro de caballería que ataca.

A continuación del jarrón y colocado delante del lado izquierdo del pilar, el escultor ha representado dos figuras masculinas, una de pie consolando y auxiliando cristianamente a un herido que arrodilla una pierna y extiende la otra con el pie vendado (Figura 5). El soldado, que lleva bigote y gorro, mira hacia arriba y eleva su brazo derecho sosteniendo en su mano resto de una posible cruz pequeña. Consideramos que esta actitud es un gesto de agradecimiento al homenajeado por la ayuda prestada a los heridos vascos. Susillo modeló la indumentaria de los dos hombres con pliegues delgados y aristados, diferentes al tratamiento suave del vestido de la alegoría. La relación de estas figuras con un tema bélico está reforzada con la presencia del armamento que figura debajo de esta escena. En el lado del pilar correspondiente a esta escena está grabado el nombre del homenajeado, "El Alcalde/ José M. de Ybarra". Este dato confirma, a nuestra opinión, que este conjunto escultórico fue modelado como monumento público de exaltación social, y uno más que quedó en proyecto dejando frustrados los deseos de sus organizadores.

\section{La muerte de dos reinas posterior a la del conde de Ybarra}

Al mes siguiente del fallecimiento del primer conde de Ybarra murió la reina María de las Mercedes de Orleans, mujer de Alfonso XII, y el Ayuntamiento acordó que su retrato se colocara en la sala capitular en consideración al cariño de la ciudad a su hija ${ }^{26}$. El pintor Manuel Cabral Bejarano entregó el cuadro días

${ }^{26}$ A.M.S., Actas Capitulares, 27-6-1878, ff. 166v-167. 
después ${ }^{27}$. El 19 de julio los regidores debatieron la propuesta de la Asociación Amigos de los Pobres que solicitaba la cesión de terrenos entre la puerta de Capuchinos y la del Sol para construir un hospital para niños y levantar un "sencillo monumento que perpetuara la memoria de la virtuosa e inolvidable Reyna $\mathrm{D}^{\mathrm{a}}$ Mercedes" 28 , y acordaron que la solicitud pasara a la comisión de obras públicas. También se determinó que la Comisión de Hacienda informara sobre la posibilidad de aportar fondos para la construcción del monumento a la reina. Este acontecimiento influyó, sin duda, en el olvido de la pérdida del conde de Ybarra.

En aquel verano sucedió la muerte de otro miembro de la Casa Real. A finales de agosto falleció la reina María Cristina de Borbón, viuda de Fernando VII, madre de Isabel II, abuela del rey Alonso XII y reina regente entre 1833 y 1840 durante la minoría de edad de su hija ${ }^{29}$. Durante meses, el Ayuntamiento trató sobre los distintos reconocimientos al recuerdo de las reinas, y en sus actas capitulares no se registra referencia a un posible monumento a don José María de Ybarra. Por eso, esta maqueta o boceto pudo haber sido encargado por otra institución pública sevillana, pero, sin duda, la falta de recursos económicos impidió hacerlo realidad. La muerte de las reinas María Cristina y María de las Mercedes eclipsaron cualquier intento de monumento público al primer conde de Ybarra.

Fecha de recepción: 7 de enero de 2017

Fecha de aceptación: 21 de enero de 2017

27 Ibidem, 8-7-1878, f. 171v.; 9-8-1878, f. 195. El 9 de agosto, el Ayuntamiento, visto el informe de asuntos especiales sobre el oficio del pintor Manuel Cabral, acordó que el alcalde García de Leaníz y los señores Talavera y Uriel o Ubiel ajustasen el pago de los honorarios, que se abonará con cargo al capítulo de imprevistos. Ibid., 23-8-1878, f. 207v. El 23 de agosto, el cabildo aprobó una distribución de fondos de 182.538 pesetas y 85 céntimos a la comisión de Hacienda, para que abonase 2.500 pesetas más la partida de imprevistos con el objeto de atender al pago del retrato de la reina ejecutado por el artista Manuel Cabral y Bejarano.

${ }^{28}$ Ibid., 19-7-1878, f. 178v. Vuelve a tratarse de esta Asociación, 9-8-1878, f. 200v.

${ }^{29}$ Ibid., 30-8-1878, f. 212v. 


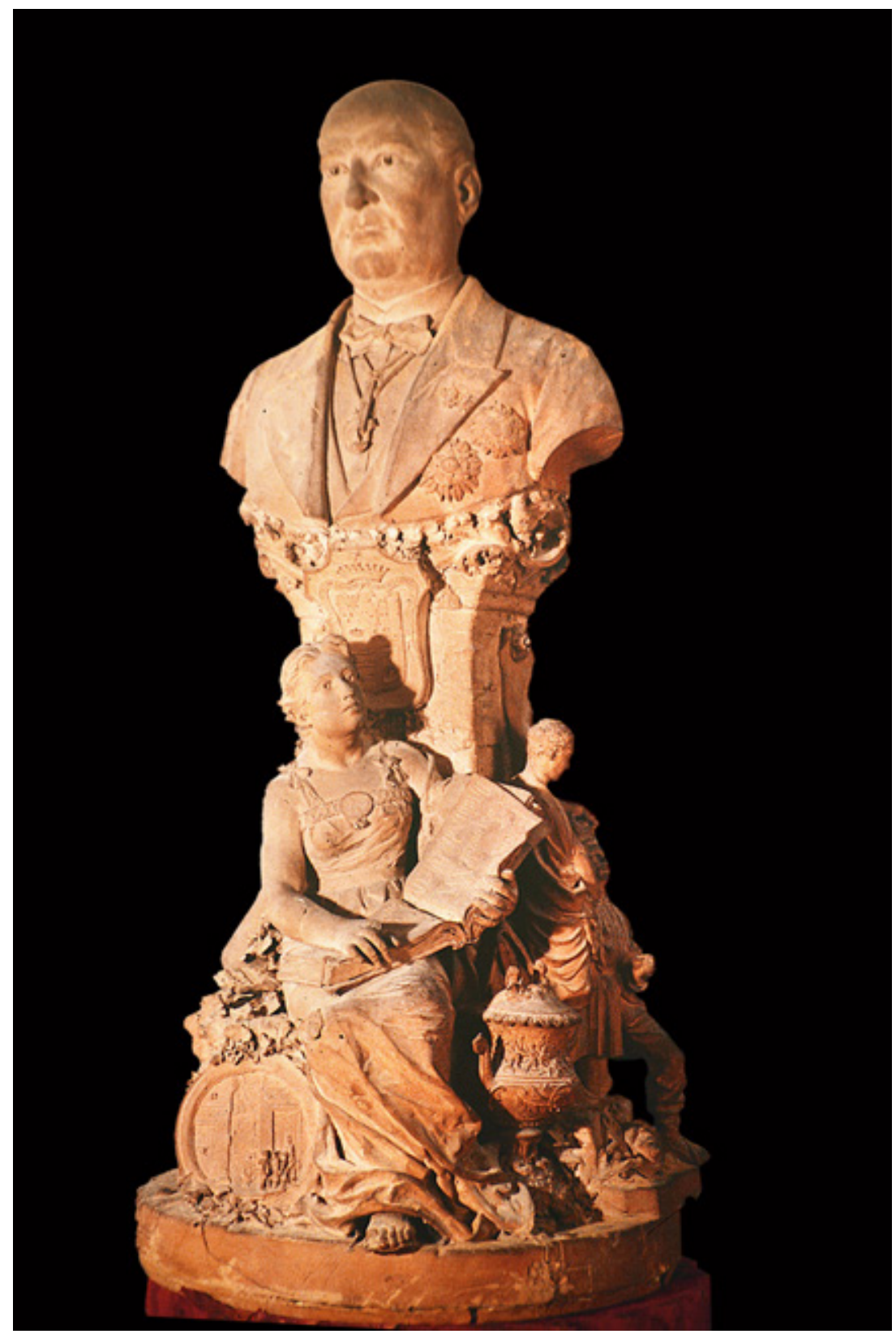

Figura 1. Antonio Susillo, Proyecto de monumento al primer conde de Ybarra, colección privada. 
Figura 2. Antonio Susillo, Alegoría (detalle), Proyecto de monumento al primer conde de Ybarra, colección privada.

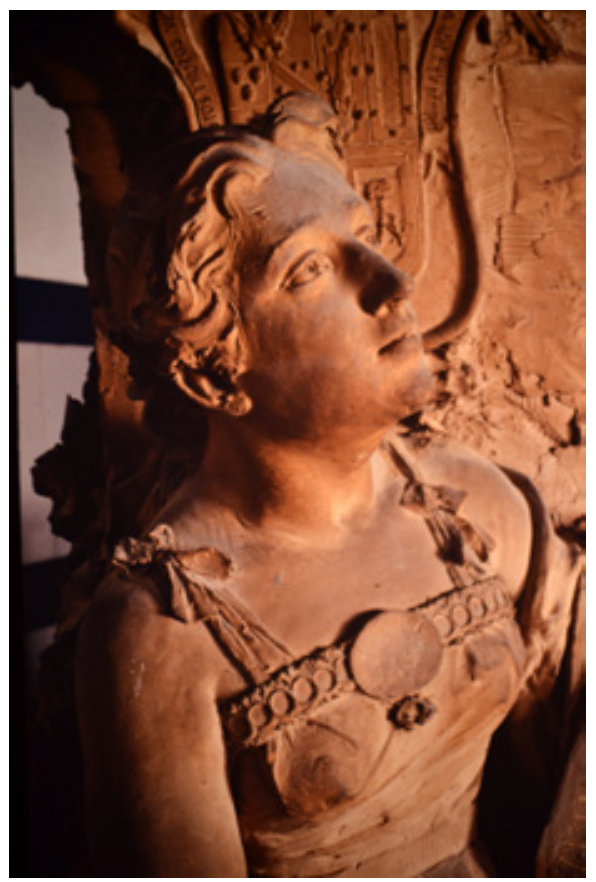

Figura 3. Antonio Susillo, Vista de la Feria de Abril de Sevilla (detalle), Proyecto de monumento al primer conde de Ybarra, colección privada.

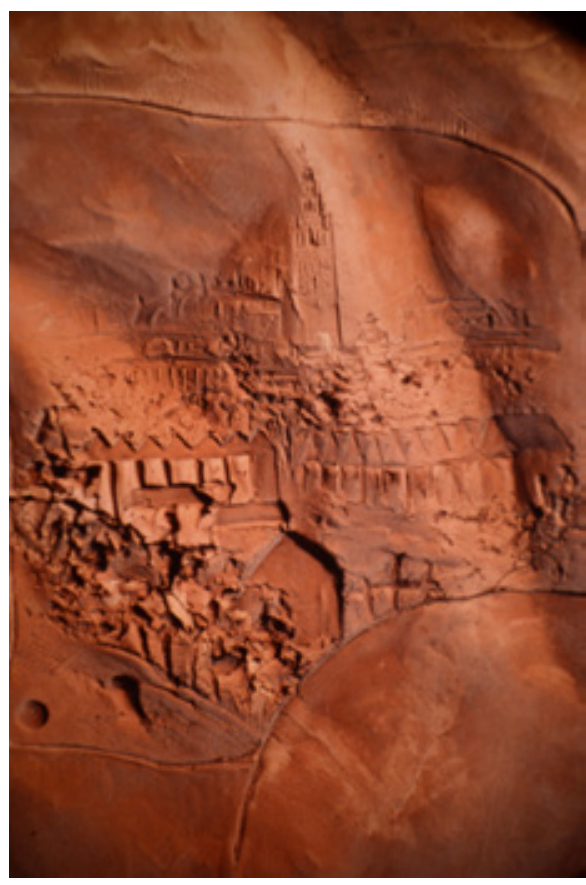

LABORATORIO DE ARTE 29 (2017), pp. 603-616, ISSN 1130-5762 e-ISSN 2253-8305 - DOI http://dx.doi.org/10.12795/LA.2017.i29.33 

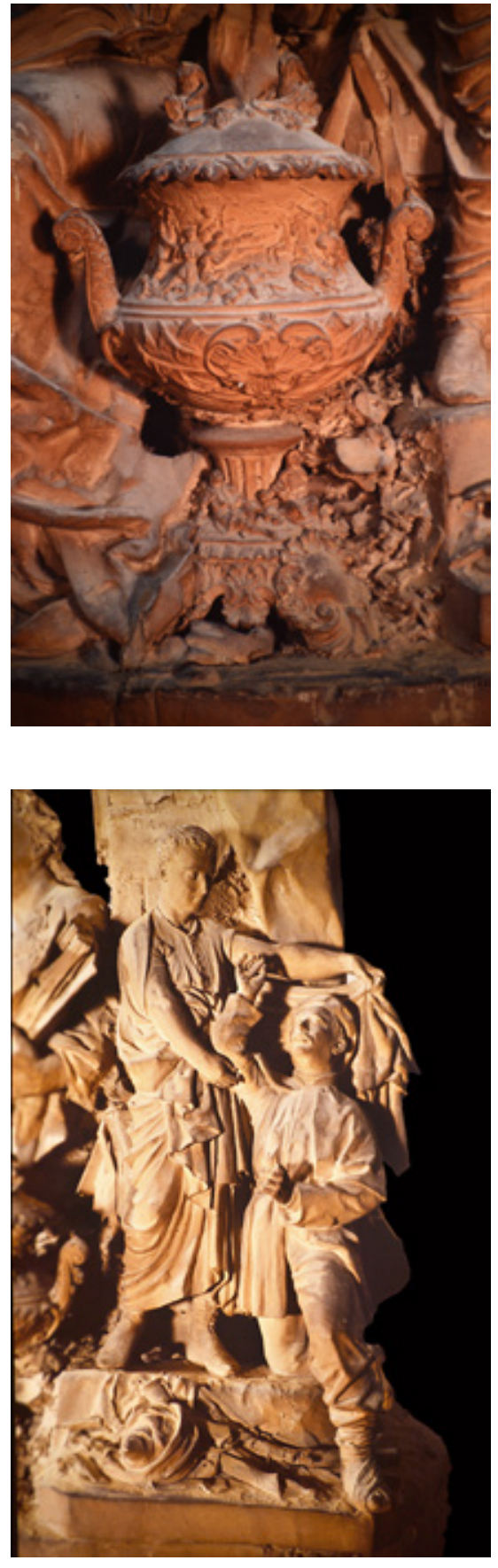

Figura 4. Antonio Susillo, Jarrón (detalle), Proyecto de monumento al primer conde de Ybarra, colección privada.

Figura 5. Antonio Susillo, Auxilio al soldado herido (detalle), Proyecto de monumento al primer conde de Ybarra, colección privada. 